
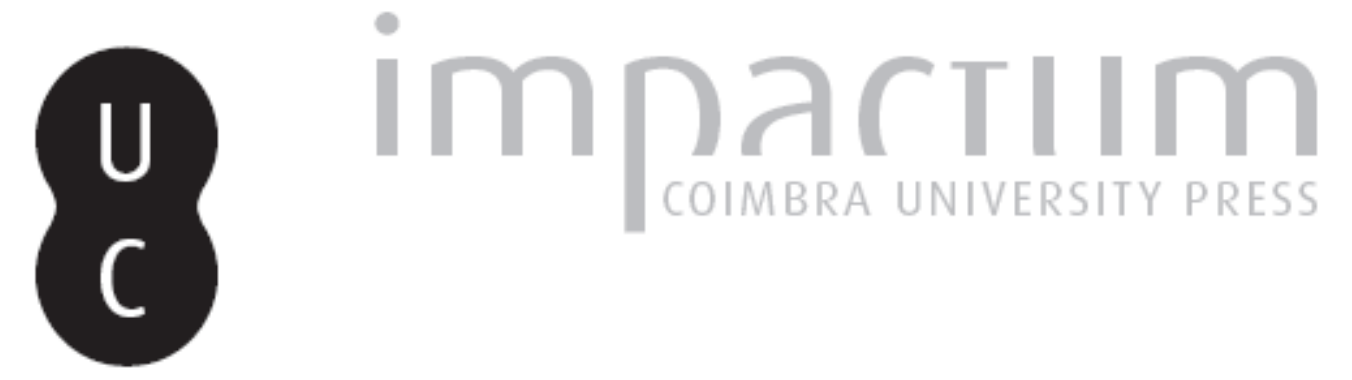

\title{
[Recensão a] CARLOS ALBERTO AUGUSTO (2014). Sons e silêncios da paisagem sonora portuguesa
}

\author{
Autor(es): $\quad$ Fernandes, João Luís
}

Publicado por: Imprensa da Universidade de Coimbra

URL persistente:

URl:http://hdl.handle.net/10316.2/37845

DOI:

DOI:http://dx.doi.org/10.14195/0870-4112_3-1_20

Accessed : $\quad$ 26-Apr-2023 13:49:43

A navegação consulta e descarregamento dos títulos inseridos nas Bibliotecas Digitais UC Digitalis, UC Pombalina e UC Impactum, pressupõem a aceitação plena e sem reservas dos Termos e Condições de Uso destas Bibliotecas Digitais, disponíveis em https://digitalis.uc.pt/pt-pt/termos.

Conforme exposto nos referidos Termos e Condições de Uso, o descarregamento de títulos de acesso restrito requer uma licença válida de autorização devendo o utilizador aceder ao(s) documento(s) a partir de um endereço de IP da instituição detentora da supramencionada licença.

Ao utilizador é apenas permitido o descarregamento para uso pessoal, pelo que o emprego do(s) título(s) descarregado(s) para outro fim, designadamente comercial, carece de autorização do respetivo autor ou editor da obra.

Na medida em que todas as obras da UC Digitalis se encontram protegidas pelo Código do Direito de Autor e Direitos Conexos e demais legislação aplicável, toda a cópia, parcial ou total, deste documento, nos casos em que é legalmente admitida, deverá conter ou fazer-se acompanhar por este aviso.

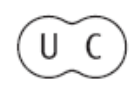




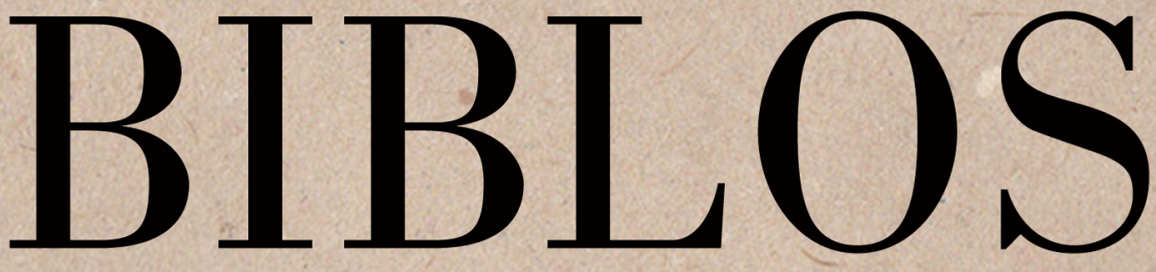

Revista da Faculdade de Letras da Universidade de Coimbra

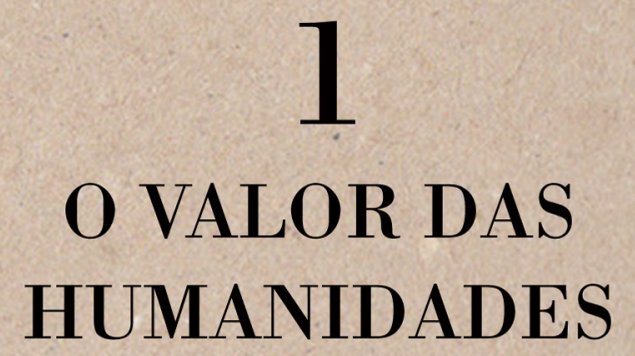

NÚMERO 1, 2015

3. ${ }^{\text {a }}$ SERIE 
CARLOS ALBERTO AUGUSTO (2014).

Sons e silêncios da paisagem sonora portuguesa.

Lisboa: Fundação Francisco Manuel dos Santos, 94 pp.

Publicado em 2014, este trabalho do compositor, designer sonoro e especialista em comunicação acústica Carlos Alberto Augusto, não é um livro de Geografia mas discute matérias que estimulam o geógrafo numa leitura mais abrangente da paisagem e das territorialidades das sociedades humanas.

Este ensaio problematiza o facto da modernidade e do progresso terem privilegiado a imagem e o domínio do visual. Contrariando esta tendência, este livro abre margem para olhares, mais amplos e complexos da relação humana com os territórios que vão organizando e vivendo.

É certo que esta exaltação do observável tem uma tradução espacial, em particular quando assistimos a tempos de estimulaçáo do consumo por paisagens policromadas e hipervisuais em realidades geográficas como, apenas dois exemplos, os centros comerciais, durante todo o ano, ou alguns espaços públicos em tempos e épocas festivas, como os períodos natalícios de celebração ocidental.

Apesar da forte componente visual, estas são também experiências multissensoriais, vivências que se reconhecem numa Geografia mais fenomenológica e aberta a territorialidades mais espessas e abrangentes. A esta análise geográfica interesssam não apenas as mudanças estéticas que acompanham as dinâmicas territoriais mas também as alteraçóes de campos sensoriais como os cheiros, os sabores ou os sons, daqui derivando conceitos anglossaxónicos como as tastescapes, as smellscapes ou, em discussão neste ensaio, as soundscapes, aqui traduzidas por paisagens sonoras.

É importante referir que, numa perspetiva pós-representacional da paisagem, os sons marcam ritmos de trabalho, práticas e acontecimentos, assim como regulam lógicas de poder político e rituais religiosos.

DOI • http://dx.doi.org/10.14195/0870-4112_3-1_20 
Como refere este autor, nas paisagens portuguesas foram notórias as mudanças recentes entre as sonoridades de matriz rural, associadas a fontes sonoras como os moinhos ou os rebanhos acompanhados pelos pastores, e os novos sons que vieram com a urbanização e o transporte rápido, traduzível no ruído que inovaçóes como as gruas, as betoneiras, os automóveis ou, nalguns lugares, os avióes, vão registando e introduzindo no quotidiano geográfico vivido pelas populaçóes.

Estas mudanças ocorrem porque se alteraram os alcances e os balanços entre as fontes sonoras que, segundo o citado Bernie Krause, se podem sistematizar em três grupos: as geofonias (os sons da natureza, do vento e do mar, por exemplo); as biofonias (produzidas pelos seres vivos, pelos animais e plantas) e as antropofonias (os sons produzidos pelo Homem, pelos meios de transporte, pelas maquinarias da industrialização, pelos novos dispositivos eletrónicos).

É na conjugação deste complexo sonoro que se vai sedimentando uma certa memória auditiva, componente relevante na construção de sentimentos topofílicos (ou topofóbicos) que podem marcar a relação de cada um com os seus lugares.

Nesta sequência, Carlos Alberto Augusto discute a função reguladora do som nas sociedades rurais pré-modernas. Os sineiros das aldeias católicas desempenhavam um papel de relevo na coesão e regulação social, anunciavam práticas, celebraçóes e momentos rituais mais ou menos rotineiros, alertavam para ocasionais perigos iminentes. Estes sinos demarcavam territórios de influência. Fonte de informação e de imposiçóes, de direitos e de deveres, o alcance do som definia uma fronteira, tinha o valor de um marco de demarcação espacial de uma ordem geográfica, a paróquia, polarizada pelo campanário da igreja.

Nesta fase, os sons da geofonia e da biofonia impunham respeito e deixavam indícios entendíveis por práticas de leitura que se perpetuaram entre as geraçóes e que, na verdade, ainda não desapareceram. Por aqui se deduzia a direção do vento e se anunciavam as intempéries. Por isso, no litoral, se escutavam o mar e as gaivotas e se tomavam decisóes práticas de trabalho, o ir ou não ir, o entrar no oceano ou o ficar em terra aguardando nova oportunidade.

Assim se acompanharam as mudanças sazonais da paisagem, pelo que estas expressavam de sonoro, como o canto das cigarras no estio do Alentejo, 
numa relação sensorial que tendemos a arrumar algures num passado indefinido mas que persistem enquanto marcadores geográficos intemporais.

Para Augusto, estes indicadores sonoros acompanhavam os ritmos do trabalho, as suas práticas e instrumentos, mas estão também na ordem e nas paisagens da guerra e dos exércitos, nos sons das marchas e nos tambores dos soldados que se organizam pela batida sequenciada de sonoridades disciplinares. Como nas procissóes religiosas, os sons das paradas militares agregam devoçóes, assim como os hinos nacionais reunem famílias e ampliam mensagens de poderes, aqueles que também através dos sinos se projetavam para longe, para os extremos da fronteira, como sinais intimidatórios face a inimigos reais ou imaginários. Ainda hoje acontece na linha de demarcação entre as duas Coreias, com a propaganda sul-coreana que uma série de altifalantes projeta para o território político do outro lado da barreira.

Estas paisagens sonoras não estáo imunes à deriva tecnológica, à inovação e às novas dinâmicas territoriais. Nos espaços rurais católicos, agora muitos sinos são elétricos. Do instrumento de bronze outrora benzido pelo pároco passou-se ao dispositivo eletrónico mais ou menos sofisticado. Na sequência de uma certa desruralização, as paisagens sonoras são agora mais tecnológicas, na cidade mas também num cada vez mais indefido e promíscuo território não urbano, ao qual chegaram novos sons, o dos festivais de verão, o das práticas de desportos radicais, mas também o dos aerogeradores ou o do comboio rápido que passa, sem paragem, deixando um rasto visual e sonoro que, logo depois, apenas se adivinha pelos carris que se inscrevem na paisagem e por ali permanecem, como muros que separam áreas que antes se atravessavam, à espera das novas carruagens que vão chegar.

No rural ou no urbano, a eletrónica modela a paisagem sonora contemporânea. O rádio e a televisão, nos espaços públicos e privados, mas também o democratizado dispositivo digital, miniaturizado e com crescente mobilidade espacial, emitindo sons que se podem transportar com facilidade. Este novo mundo trouxe ambientes mais complexos e difusos.

Por um lado, assiste-se a uma certa atomização acústica. Também pela paisagem sonora se afirma um certo individualismo já discutido por autores como Lipovetsky. Estar num grupo não significa interagir e a proximidade física 
pode equivaler a um distanciamento sonoro, graças a dispositivos, quase sempre híbridos, individuais e portáteis, que insularizam as experiências territoriais.

Por outro, a mudança (e multiplicação) das fontes sonoras eletrónicas pode criar ambientes invasivos, porventura anti-terapêuticos, com a sobreposição de sons, música, ruídos, informaçóes, apelos, numa esquizofonia turbulenta, confusa, hostil. Esta sonoridade já não é a do ritual religioso ou do trabalho, a da defesa da fronteira ou a da organização do exército. Em muitos casos, como no centro comercial pósmoderno, é a do estímulo ao consumo, a da permanente música de fundo (muzak) que envolve o transeunte-consumidor numa certa ilusão de conforto e bem-estar.

Este adormecimento tácito remete-nos para os diferentes modos de perceção e escuta da paisagem sonora (cada um com as suas territorialidades), sistematizados por Barry Truax, citado neste ensaio: a escuta em sonda (escutase tudo à volta mas foca-se, de forma deliberada, um único som); a escuta em espera (ouve-se o ambiente sonoro em fundo e, embora se possam identificar os sons que dele fazem parte, estes não se distinguem) e a escuta em fundo (não se distingue nenhum som em particular).

Para Carlos Alberto Augusto, estas múltiplas leituras da paisagem sonora têm uma pertinência pragmática. Desde logo porque, nas sociedades contemporâneas, é ao sonoro que se imputem grande parte dos conflitos territoriais de microescala. Apesar da acústica estar longe da preocupação central das associações ecologistas, o ruído é agora considerado uma disfunção ambiental que exige respostas objetivas. Em Portugal, apenas a integração europeia permitiu passos mais firmes (com o primeiro Regulamento Geral do Ruído, de 1987) na defesa do bom ambiente sonoro. No entanto, segundo este ensaio, a legislação protege pouco as vítimas. As que podem, aquelas que têm capital de mobilidade, mais que defender os seus direitos, acabam por mudar de lugar, afastando-se do foco de agressão sonora. Ainda assim, com estes novos paradigmas, a engenharia acústica entrou no planeamento urbano, numa paisagem sonora que é, afinal, responsabilidade coletiva.

Por tudo isso, Carlos Alberto Augusto dedica um capítulo ao silêncio, à capacidade de evitar o ruído, de criação de espaços de reserva e conforto, de 
territórios de ausência de som, supressão essa que é, no limite, uma utopia pois sempre se escutará algo.

Ainda assim, o silêncio, como respeito e celebração, como arma de resistência (o direito a mantermo-nos em silêncio, ou o sussurro silencioso para transmitir mensagens subversivas em regimes autoritários) mas também como imposição disciplinar (silenciar um grupo para se impor uma mensagem), será sempre um instrumento de poder.

Nesse sentido, é importante analisar as estratégias, estatais ou outras, para regulação e imposição do silêncio, objeto de leituras diferenciadas consoante os contextos culturais: será uma ameaça, nalguns casos; pode ser um sinal de desprezo pelo conjunto, uma barreira à comunicaçáo; ou, noutras circunstâncias, uma condição essencial para a saúde.

Numa cidade barulhenta, fazer ruído estará ao alcance de todos mas a delimitação de ilhas sonoras é um poder limitado a poucos, um poder que exige energia e capital para levantamento de barreiras (físicas ou outras) que garantam o conforto, numa estratégia que reforçou a perceção de segurança auto-confinada que acompanha os denominados condomínios privados.

Por isso, pela entrada do som no planeamento urbano em particular e no ordenamento do território em geral, se calculam os horizontes acústicos, mais acanhados nas cidades, mais largos em paisagens extensas, com menos densidade de construído.

Para finalizar, retomando a ideia da acústica como memória e do som como um amplo espectro que vai da música ao ruído, este ensaio remete-nos para a ideia de paisagem sonora enquanto campo de inovação e regulação mas também enquanto herança a conhecer e a preservar, como se comprova por uma parte significativa dos bens reconhecidos pela Unesco no âmbito da lista classificada do Património Imaterial da Humanidade, que regista o valor da oralidade e do sonoro.

\author{
JOÃO LUÍS FERNANDES \\ jfernandes@fl.uc.pt \\ Faculdade de Letras da Universidade de Coimbra \\ CEGOT - Centro de Estudos de Geografia e Ordenamento do Território
}

